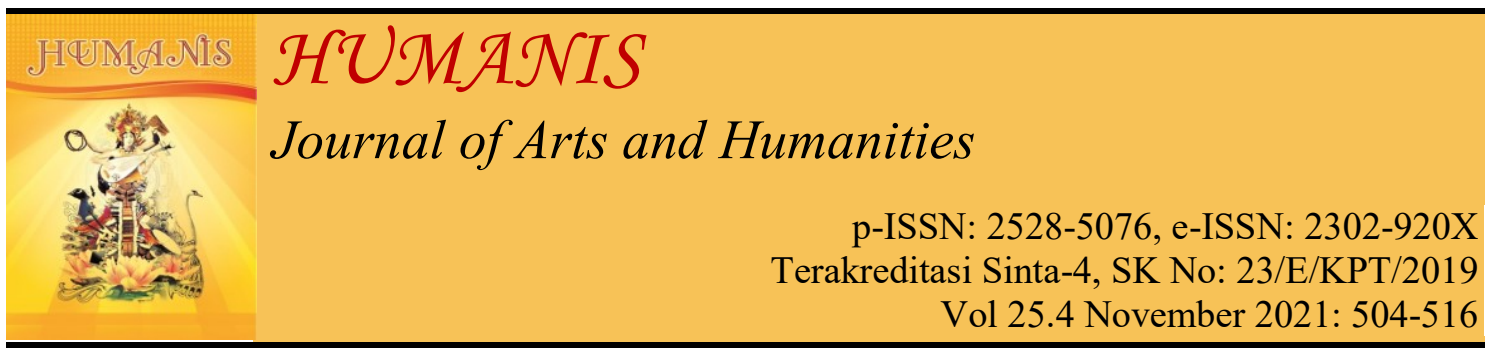

\title{
Pengaruh Narasi pada Seni Lukis Tradisi Bali: Studi Bahasa Rupa Lukisan Wayang Kamasan dan I Ketut Gede Singaraja
}

\author{
Dewa Gede Purwita \\ Institut Desain dan Bisnis Bali \\ Email korespondensi: dewagdepurwita@std-bali.ac.id
}

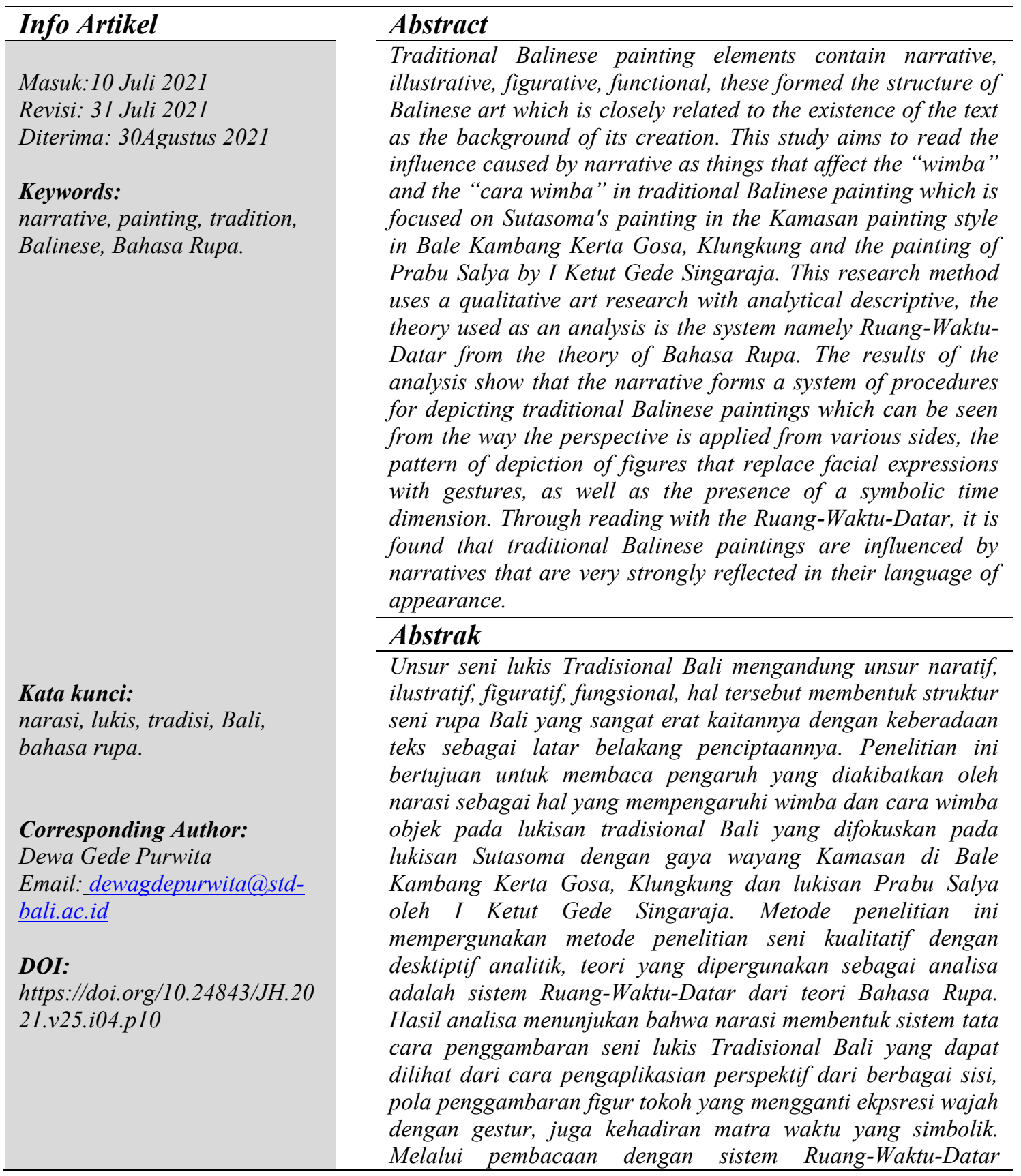




\section{PENDAHULUAN}

Sebagaimana anak-anak yang memegang pensil kemudian mencoratcoret permukaan tembok, mereka menghasilkan gambaran yang di dalam dunia seni rupa dinamakan dengan naif atau doodle art bagi orang dewasa secara umum mungkin tidak berarti apa-apa, atau justru memarahi anak mereka sebab mengotori tembok, sebagian mungkin menikmati distorsi garis juga warnawarni, dan sebagaian orang tua mungkin mencoba menganalisis apa yang digambar oleh anak mereka. Apa yang dilakukan oleh anak-anak tersebut tidak sekedar luapan emosi belaka namun justru mereka sedang bermain dengan realitas pikirannya, bahwa ada realitas naratif yang ingin diungkapkan melalui kerja motorik yang tentu belum terlatih sebagaimana juru gambar yang mumpuni menghadirkan kenyataan atau realitas yang diinginkan pada karyanya.

Dunia anak-anak memang dipenuhi dengan imajinasi, dunia bermain, dapat dikatakan bahwa mereka hidup dalam dua dunia, yang pertama adalah dunia realitasnya dan dunia kedua adalah dunia khayal. Dalam dunia realitasnya anakanak tentu hadir dengan segala bentuk kembangan pengindra mata, hidung, kulit, lidah, telinga, bahwa kenyataannya mereka pada awal perkembangan lebih kepada proses meniru yang dicerap melalui panca indra, sedangkan dunia khayal sebagai dunia kedua bagi anakanak adalah tempat mereka hidup dalam imaji-imaji yang telah dicerap oleh panca indra. Sebagai contoh misalkan bagaimana seorang anak-anak meniru superhero, atau memperagakan tarian, juga berkhayal hidup dalam dunia keputren ala princess dengan memanfaatkan segala material yang ada disekitarnya. Mereka seolah belum dapat memilah yang mana realitas yang mana imaji.

Analogi anak-anak tadi memiliki relasi terhadap bagaimana pengaruh narasi terhadap seni lukis khususnya seni lukis tradisi di Bali. Bahwa seorang pelukis hidup dalam dua dunia tersebut, realitas dan imaji, kesamaan praktiknya adalah bahwa seorang pelukis dan anakanak sama-sama memiliki visi menghadirkan atau mewujudkan dunia imaji mereka ke dalam dunia reliatas pada suatu bidang, perbedaannya hanya yang satu telah memahami tata cara melukis dan yang lagi satu belum memahami. Lantas apa hubungannya dengan narasi dan seni lukis tradisi? Tentu, bahwa narasi dibangun melalui teks yang mendorong munculnya imaji sedangkan seni lukis tradisi adalah media yang menampung segala hasil kreatif yang dikerjakan oleh seniman, oleh sebab itu, lukisan adalah realitas yang tercipta melalui dorongan yang dipengaruhi oleh narasi sebuah teks.

Setiap teks tentu mengandung norma terlebih tradisi dengan aturan yang jelas, norma kemudian mengatur segala hal yang masuk ke dalam wilayahnya bahkan dapat mempengaruhi apa yang tercpita kemudian. Sebagaimana seni lukis tradisi yang melandaskan penciptaannya dengan latar belakang teks yang dapat dikatakan ketat, tentang norma-norma yang telah disetujui, tentang konvensi-konvensi yang baku, dapat dikatakan kemudian bahwa teks yang didalamnya mengandung narasi memiliki pengaruh besar dalam penciptaan seni lukis khsusunya seni lukis tradisi Bali. Terminologi seni lukis tradisi Bali menjadi identitas kultural dalam kontruksi sejarah seni rupa Indonesia 
yang khas, indentitas kultural tersebut oleh Irianto (2017:98) dilihat dari fungsi sosial dan ritual, kesenian tradisional juga dipercaya masyarakat pendukung tidak sekadar sebagai hiburan yang menciptakan kegembiraan, namun ia juga menjadi media yang mampu memfasilitasi doa dan harapan mereka.

Seni lukis tradisi atau dalam istilah Joseph Fischer dan Thomas Cooper disebut folk art adalah seni lukis yang memiliki relasi terhadap dunia wayang atau yang masih khusus dikerjakan dengan teknik pewarnaan yang diturunkan dari generasi ke generasi seperti nyigar mangsi, ngucek atau ngabur, nyawi. figur-figur wayang merupakan gambaran manusia dalam kehidupan sehari-hari, yang dapat dijadikan sebagai media pendidikan terutama pendidikan budi pekerti (Rafsanjani, 2014:36). Figur wayang sebagai media pendidikan hari-hari ini di Bali dapat dijumpai di Kerta Gosa, Klungkung, dikenal mempunyai pengaruh menyeluruh di medan sosial seni rupa Bali.

Lukisan wayang Kamasan dalam sejarah seni rupa Bali masuk ke dalam genre seni rupa klasik karena unsur-unsur rupanya menjadi acuan di dalam membuat gambar atau lukisan wayang di Bali yang tidak hanya berlaku pada masa puncaknya akan tetapi berlanjut hingga masa-masa setelahnya sebagai acuan proporsionalitas lukisan wayang. Sebagaimana Irfansyah (2013 : 206) dalam Dwija Putra (2018:131) mengenai masa puncak kesenian di Kerajaan Gelgel adalah pada masa pemerintahan raja Dalem Waturenggong yang memerintah sekitar tahun 1460-1550 Masehi, kesenian mencapai puncak keemasan dan disebut juga masa kesenian klasik, kesenian klasik tersebut yang melahirkan pakem atau tolak ukur kesenian setelahnya yang disebut tradisional. Dengan demikian segala hal yang berwujud wayang disebut sebagai citra wayang.
Rujukan menggambar figur wayang yang proporsional melalui deretan proses yang panjang tentu menempatkan gambar wayang Kamasan sebagai puncak peradaban seni rupa Bali, oleh semua seniman di Desa Kamasan Klungkung sampai hari ini masih menganut sistem proporsional dalam proses menggambar yang diwarisi turun-temurun yaitu ngedum karang, jajar wayang, nyeraki, molog-mologin, ngereka, ngewarna (ngudanin -ngewayahin), ngerus, nyawi (nguleng util, ngerincem), neling, nyocain, mulunin, mutihin (Purwita, 2019:211). Proses tersebut tidak hanya memberikan struktur figur wayang yang proporsional melainkan juga membentuk keserasian antara figur sebagai objek dengan bidang gambar yang membentuk komposisi.

Seni gambar wayang Kamasan memberi pengaruh besar terhadap kemunculan seni gambar wayang di hampir seluruh wilayah di Bali, wilayah Denpasar-Badung dalam arsip Van der Tuuk tercatat dua orang pelukis handal yang menuliskan nama pada karyanya pada abad ke-19 yaitu Ida Putu Hema dari Griya Pratoda dan Ida Made Telaga dari Griya Telaga, Sanur (Hinzler, 1986:4).

Di Tabanan seni gambar wayangnya berkembang pesat di Desa Kerambitan, di Jembrana meskipun tergolong muda kesan wayang yang melekat tentu merujuk kepada penggambaran wayang ala Kamasan meski bentuknya lebih sederhana dengan teknik sulaman benang, di Buleleng dengan ekspresifnya I Ketut Gede Singaraja juga pelukis lainnya yang menjadikan figur wayang menjadi khas gaya Blelengan, Karangasem dengan keberadaan puri dan griya brahmana sebagai patron meskipun dalam perkembangannya tidak semasif di Kerambitan, di Gianyar dengan wayang Batuan, juga tradisi di wilayah Ubud dan sekitarnya, dan informasi terbaru ternyata 
di Bangli juga berkembang sebuah genre lukisan wayang dengan pendekatan yang lebih realis-naturalistik. Segala bentuk penggayaan figur wayang di masingmasing daerah tentu tidak terlepas dari keinginan untuk menampilkan visual yang khas kedaerahan, selanjutnya disebut juga sebagai corak atau gaya.

Meskipun demikian, bagaimanapun juga bentuk corak dari lukisan-lukisan tersebut tidak terlepas dari konstruksi narasi yang memiliki pengaruh besar dalam mewujudkan karya lukisan tradisional Bali. Sebagaimana tiga unsur seni lukis tradisi adalah naratif, figuratif dan ilustratif, teks memiliki peranan sangat besar membentuk stuktur alam imaji dan pikiran pelukis, hal yang sama dengan imaji dan alam pikiran yang dicerap oleh panca indra oleh anak-anak. Apa yang dikatakan sebagai naivisme pada anak-anak dan struktur tradisi yang tidak rasionalis, elemen-elemen estetik pada lukisan tradisi adalah bentuk bahasa rupa yang dikontruksi oleh teks.

Pada kasus tentang bagaimana narasi mempengaruhi bahasa rupa seni lukis tradisional Bali mempergunakan karya lukisan dari I Ketut Gede Singaraja yang tercatat aktif melukis pada tahun 1870awal 1900. Semua karya lukisannya dikerjakan pada medium kertas dan cat air yang diberikan oleh Van der Tuuk yang memang sebagian besar diperuntukan untuk ilustrasi proyek ambisiusnya menyusun kamus bahasa Kawi (Jawa Kuno)-Bali-Belanda. Perbandingan lainnya mempergunakan potongan adegan dari gambar Sutasoma di Bale Kambang kompleks Kerta Gosa Klungkung yang merupakan kelanjutan dari seni gambar wayang Kamasan yang telah hidup berabad-abad silam.

Kedua objek tersebut dipilih untuk mewakili studi tentang pengaruh narasi terhadap visual, lebih dari itu baik gambar wayang Kamasan dan karya lukisan I Ketut Gede Singaraja masing- masing mewakili eksistensi gambar dengan tematik wayang, gambar Kamasan di satu sisi mewakili dari wilayah kelahiran sebuah pakem gambar tradisional Bali, lukisan I Ketut Gede Singaraja mewakili sisi perkembangan yang signifikan dari gaya gambar wayang Kamasan atau sebagai hasil karya dari masa peralihan dan juga awal inovasi artistik seni gambar menjadi seni lukis wayang dengan berubahnya teknik pengerjaan terutama perlakuan terhadap warna.

Meskipun di dalam perkembangannya terdapat perubahan dari sisi teknis, tematik gambar pewayangan tetap menampilkan adegan yang ditransformasikan melalui teks menjadi rupa. Dengan demikian maka dapat ditarik sebuah rumusan masalah tentang bagaimanakah pengaruh narasi terhadap seni lukis tradisi di Bali? Tulisan ini bertujuan untuk menyelidiki dan menganalisa pengaruh-pengaruh yang ditimbulkan dari latar belakang penciptaan seni lukis tradisi Bali yang sangat lekat dengan keberadaan teks sebagai sumber penggambaran yang sangat naratif, ilustratif, dan juga figuratif, lebih dari itu juga bagaimana pengaruhnya terhadap cara wimba pelukis Bali mengapresiasi teks sebagai bentuk relasi terhadap unsur-unsur estetik yang menyusun sebuah lukisan tradisi.

\section{METODE DAN TEORI}

Merujuk uraian pada latar belakang maka dapat ditentukan metode penelitian yang dipergunakan dalam memahami pengaruh narasi terhadap seni lukis Bali mempergunakan metode penulisan deskriptif analitik dengan pendekatan penelitian kualitatif, melalui metode tersebut tentu diharapkan pada penjabaran secara deskriptif yang berdasar pada analisa-analisa komponen visual juga teks yang melandasi terciptanya sebuah lukisan. Sebagaimana 
dijelaskan oleh Rohidi (2011:46) bahwa tipe penelitian kualitatif dalam konteks penelitian seni memusatkan perhatian pada pemahaman makna teks atau tindakan yang mengarahkan penelitian pada pengamatan tema-tema, dan penafsiran. Yang pertama mewujudkan fenomenologi dan yang kedua mewujudkan kajian kasus dan sejarah kehidupan di satu sisi, dan si sisi lainnya mewujudkan hermeneutik.

Sebagai pisau bedah untuk menganalisa mempergunakan teori bahasa rupa yang dirumuskan oleh Primadi Tambrani, bahasa rupa sangat efektif di dalam menganalisa gambar atau lukisan prasejarah, gambar anak-anak, relief, gambar atau lukisan tradisional bahkan juga lukisan kontemporer. Teori ini menitik beratkan pada persoalan konteks ruang dan waktu, sudut pandang/perspektif, dan narasi pada karya seni, Primadi Tambrani merumuskan sistem analisa bahasa rupa ke dalam kerangka sistem RWD (RuangWaktu-Datar) sebagaimana dijelaskan oleh Tambrani (2012:136) bahwa sistem RWD menggambar dari aneka arah, aneka jarak dan aneka waktu. Yang digambar menjadi sekuen yang terdiri dari sejumlah adegan dan objek-objek bergerak dalam ruang dan waktu. Media yang dapat bercerita adalah media bermatra waktu, maka ia juga bisa bercerita dengan memanfaatkan cara wimba dan tata ungkapnya, bukan keindahannya, RWD dengan bahasa rupanya memang lebih mementingkan pesannya, ceritanya, komunikasinya.

Sistem RWD berbeda dengan perspektif gambar ala Barat yang matematis kemudian disebut NPM (Naturalis-Perspektif-Momenopname),

dijelaskan oleh Tambrani (2012:136) bahwa NPM menggambar dari satu arah atau satu jarak atau satu waktu, dianalogikan dengan kerja mekanik mesin kamera yang sekali memencet shutter gambar menjadi beku, apa yang ditangkap mata itu yang digambarkan, apa yang digambarkan diabadikan menjadi sebuah adegan yang berupa gambar mati (still picture) dimana objekobjek dipenjarakan dalam frame. Oleh sebab itu gambar kehilangan matra waktu walaupun memperoleh ilusi ruang yang kuat. Still picture mempergunakan pola geometrik perspektif yaitu sistem pengembangan matematis, disebut juga perspektif linier sebagai garis bantu untuk menciptakan kedalaman ilusi optik (Adams, 2021:14).

Oleh sebabnya, ketika menganalisa gambar atau lukisan prasejarah, gambar anak-anak, gambar atau lukisan tradisi, relief, dengan metode NPM maka apa yang didapatkan adalah suatu gambar dengan bentuk yang tidak logis, tidak proporsional, begitu juga sebaliknya ketika karya seni tersebut dibaca dengan sistem RWD maka yang didapatkan adalah kekayaan sudut pandang atau perspektif (multi-perspektif), distorsi ruang dan bentuk, metode rontgen (sinar $\mathrm{x})$, dan kekuatan naratif. Dengan demikian teori bahasa rupa dipandang memiliki relevansi yang kuat di dalam menganalisa pengaruh narasi terhadap seni lukis tradisional Bali.

\section{HASIL DAN PEMBAHASAN}

Seperti telah disebutkan lebih awal, mayoritas besar lukisan-lukisan tradisional di atas kain adalah naratif. Imajinasi orang Bali sejak masa kanakkanak telah begitu penuh dengan ceriteraceritera yang tidak terhitung, begitu gamblang mereka sadar pada para pahlawan serta nasib-nasib mereka (Holt, 2000:256). Holt memberikan sebuah gambaran bahwa imajinasi orang Bali yang sejak masih pada masa kanak-kanak pada masa lalu dibentuk oleh narasi yang dalam konteksnya adalah cerita pewayangan, alur cerita dan tokoh figur pewayangan menjadi pemicu imajinasi 
orang Bali dalam memenuhi bidang lukisan dua dimensinya.

Kepentingan untuk tersampainya proses komunikasi melalui gambar adalah hal utama pada seni lukis tradisional Bali, relasi antara teks verbal (tulisan) teks visual (rupa) saling berkait, terutama membaca seni rupa klasik dan tradisi yang mendasarkan penciptaannya melalui interpretasi teks verbal berupa tulisan, sebagaimana Atika Laila et al. (2021) menyatakan "teks visual mampu menjelaskan teks verbal begitu juga teks verbal dapat dijelaskan oleh visual".

Dalam konteks seni rupa klasik dan tradisi Bali, aspek narasi menjadi landasan yang kuat di dalam membentuk gaya gambarnya, hal tersebut dikarenakan pertimbangan antara hubungan seni lukis dengan wilayah fungsi religiusnya yaitu meneruskan narasi yang terkandung dalam ajaranajaran agama memiliki relasi terhadap filsafat hidup manusia menurut sastrasastranya. Pandangan tentang fungsionalisnya seni tradisional Bali selalu digambarkan dengan benda yang selalu memiliki fungsi dalam hubungannya dengan kebudayaan, sebagaimana Fischer \& Cooper (1998:6) menulis bahwa "every artistic was destined for a specific use in the traditional culture. There was not 'art' divorced from function, no 'art for art's sake', no art made for sale as art'."

Narasi pada dunia kesusastraan berada dalam prosa atau cerita rekaan di dalamnya terklasifikasi lebih detail atas roman, novel, novelet, cerita bersambung, dan cerita pendek. Hakikat prosa adalah peristiwa strukturnya dibagi menjadi dua yaitu struktur fisik dan tematik. Struktur fisik, prosa terdiri dari aspek peristiwa, tokoh, penokohan, setting, alur. Di dalam sebuah peristiwa tokoh dan penokohan menjadi pusat sehingga keduanya (peristiwa dan tokoh) bagian utama fisik cerita (Saidi,
2007:299). Dengan memahami apa itu narasi dalam dunia kesusastraan maka kehadiran narasi dalam seni rupa harus terdapat dua unsur atau lebih yang membangun sebuah peristiwa, dapat berupa tokoh dengan setting ruang. Lebih lanjut mengenai narasi dalam seni rupa dijelaskan oleh Saidi bahwa jika relasi demikian terbangun, elemen-elemen lain dan ceritanya akan terbangun secara in absentia (inplisit). Cerita yang terbangun secara in absentia adalah cerita yang secara imajinatif terbangun di benak apresiator setelah melihat gambar (after image).

Efek dari after image tersebut adalah kondisi ketika apresiator telah menerima pesan dari narasi sebuah karya seni lukis, oleh sebabnya pesan harus tersampaikan dengan jelas meski melalui pemilihan potongan fragmen yang ketat juga objek figur atau benda yang simbolik. Bahasa rupa kemudian juga berhubungan dengan penggunaan ikonografi pada setiap figur yang berfungsi menyatakan tokoh tertentu juga strata atau status sosial dari tokoh yang dihadirkan.

Dengan demikian narasi menjadi hal pertama yang harus dipahami oleh seorang pelukis tradisi sedangkan aspek figuratif yang kedua dan ilustratif yang ketiga, sebab untuk mencapai sebuah konstruksi ilustratif maka sisi penggambaran yang figuratif haruslah sesuai dengan narasi yang dipilih untuk dimunculkan. Melalui proses ini maka terjadi transformasi dari teks ke rupa, sejauh ini proses transformasi lintas medium oleh penulis dipergunakan istilah operasi adaptasi yang dipinjam dari istilah transformasi komik menjadi film oleh Jones dalam Purbasari et al. (2013:91) yang menguraikan sebuah rangkaian operasi adaptasi yang berdasarkan pada hubungan narasi dan gaya sehingga proses adaptasi dapat dibedakan menjadi dua macam yaitu adaptasi struktural dan adaptasi tematik. 
Secara tematik dalam teks yang diadaptasi menjadi sebuah gambar tentu tidak terjadi perubahan, yang berubah secara signifikan adalah struktur dari teks menjadi gambar. Dalam konteks pengaruh narasi terhadap seni lukis tradisi Bali bahwa unsur narasi yaitu peristiwa yang di dalamnya terdapat tokoh dan setting ditransformasikan ke dalam bentuk unsur naratif visual, pada prosesnya terjadi pembentukan sekaligus penggayaan ikonografi yang ketat agar tidak terjadi kesalahan persepsi mengenai tokoh dan setting dalam sebuah peristiwa.

Gaya gambar demikianlah yang disoroti dalam sistem Ruang-WaktuDatar sekaligus kemudian berdampak pada tata cara penggambarannya yang tidak realistik dan dianggap tidak logis melalui sistem perspektif naturalistik sebagaimana penjelasan Yudoseputro (2008:139) menyatakan bahwa gaya tidak realistis ini juga tampak dalam penggarapan ruang antara latar depan dan latar belakang yang tidak mengacu pada hukum perspektif dalam tradisi seni lukis Barat. Hukum perpsektif Barat yang dimaksud adalah sistem NPM yang bertitik tolak pada aspek naturalisme yang mengacu kepada Harris (2006:211) "naturalism exists with visual style and desire to depict, as accurately as possible, the appearances of things in the world."

Untuk memahami peran narasi pada seni lukis tradisi Bali melalui sistem RWD dapat dilihat pada keseluruhan panel lukisan wayang kamasan di kompleks Kerta Gosa, pada tulisan ini lebih fokus pada cerita Sutasoma yang terdapat pada Bale Kambang. Lukisan dengan lukisan Sutasoma dibuat dengan gaya wayang Kamasan, teks aslinya berjudul Kakawin Sutasoma ditulis oleh Mpu Tantular. Cerita tentang Sutasoma berdasarkan pada filosofi agama Buddha yang pada akhir ceritanya bermuara pada sinkretrisme Siwa-Buddha. Dalam konteks ini pilihan fragmen akan difokuskan pada potongan cerita ketika Sutasoma Berhadapan dengan Prabu Jayantaka, Prabu Jayantaka sendiri lebih dikenal sebagai Purusadha Santa.

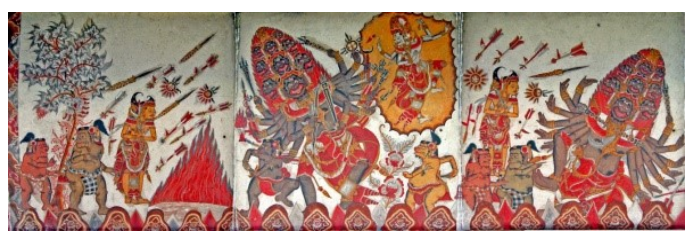

Gambar 1. Pertarungan Sutasoma dengan Jayantaka - Lukisan di Bale Kambang Kerta Gosa

Sumber: Dokumentasi Pribadi

Merujuk pada Suarka,dkk. (2012:97-99) dari kiri ke kanan menceritakan

"Sang Sutasoma dihantam berbagai senjata, dengan segala kesaktiannya api dibalas dengan air hujan, dan begitu juga semua panah-panah yang menghujamnya berubah menjadi bunga. Senjata konta menjadi pudak, tombak pendek menjadi bunga bakung, panah yang tajam dan banyak menjadi bunga melati, raung sangka kala dan terompet menjadi sundari, busur dan keris menjadi gadung, angsoka, dan kemoning, bajra, musala dan trisula menjadi bunga cempaka dan nagasari, serta pohon parijata berundag-undag jelmaan senjata sakti".

Dilanjutkan dengan "Sang Sutasoma menjadi Sang Hyang Wairocana (Sang Hyang Jina Murti), berhadapan dengan Triwikrama Purusadha sebagai Sang Hyang Maha Rudra Murti."

Pada narasi terakhir pertarungan Sutasoma dengan Jayantaka diceritakan "Triwikrama Sang Hyang Maha Rudra Murti (Raksasa Purusadha) tak mampu menghadapi Sang Hyang Buddha Jina Murti (Sutasoma), Sang Hyang Rudra Murti (Siwa) sadar bahwa Sang Hyang Jina (Buddha) keduanya menyatu 
sehingga amarah Sang Hyang Rudra Murti menjadi reda."

Pada Gambar 1. kebutuhan ilustrasi gambar yang berdasarkan pada narasi perang antara Sutasoma dengan Jayantaka (Raksasa Purusadha) adalah adegan perang satu lawan satu oleh sebabnya tidak banyak figur prajurit yang ditampilkan pada tiga panel cerita, kebutuhan menyambung narasi peperangan duel ini membuat pelukis menghadirkan matra waktu pada potongan fragmen ini, matra waktu dapat disimbolkan dengan segala hal dalam lukisan tradisional Bali yang dalam konteks lukisan ini digambarkan dengan adanya dua tokoh Sutasoma dengan ikonografi mahkota supit surang, berkulit putih yang mencerminkan tokoh halus, juga dengan sikap meditatif dibuat pada sikap murda tangan yang konsisten, selain sutasoma terdapat juga dua tokoh punakawan yang juga digambarkan ulang pada sisi kiri dan kanan bidang gambar, posisinya selalu di bawah Sutasoma. Raksasa Purusadha juga digambarkan dua kali dengan penggambaran raksasa bertubuh gelap, bertangan dan berkepala banyak. Yang digambarkan satu kali hanya dua punakawan raksasa Purusadha dan Bhatara Siwa.

Matra waktu juga tercermin pada senjata-senjata yang mengarah ke tubuh Sutasoma dengan ujungnya digambarkan menjadi bunga padahal nyatanya raksasa Purusadha masih menggenggam senjata di tangan-tangannya, penggambaran model ini selain mengungkapkan matra waktu juga memiliki relasi pada teks naratifnya ketika sang raksasa menghujani tubuh Sutasoma dengan berbagai senjata namun seluruh senjatasenjata tersebut berubah menjadi bunga dan tumbuhan. Akan tetapi ketika kita menggeser mata kita ke ujung kanan panel fragmen terlihat tangan-tangan raksasa Purusadha tidak memegang apa- apa terutama pada tangan-tangan sisi kanan sedangkan tangan sisi kirinya masih memegang satu senjata. Pada sistem RWD mimik wajah tidak begitu ditonjolkan, sebaliknya gestur tubuh figur yang dipergunakan sebagai pengganti ekspresi wajah sebagaimana yang tersurat dalam penggambaran raksasa Purusadha yang pada akhirnya dalam teks dijelaskan tidak mampu mengalahkan meditatifnya Sutosoma.

Dengan demikian sejatinya adegan telah berganti yang sejalan dengan narasi bahwa Sang Hyang Maha Rudra Murti (Raksasa Purusadha) tidak mampu menandingi Sang Hyang Jina Murti yaitu Sutama, menariknya figur Sutasoma sendiri tidak pernah disiratkan berubah wujud, gestur tubuhnya pun masih tetap sama dengan cara wimba yang teguh, tenang, meditatif dengan sikap tangan mudra. Jadi dapat dikatakan bahwa kebutuhan pelukis adalah menghadirkan kedahsyatan perubahan wujud Sutasoma dengan meditatif, sejalan dengan sikap Buddha yang sederhana, penuh ketenangan, berbanding terbalik dengan penggambaran figur Jayantaka dalam kedahsyatan perubahan wujudnya yang besar dengan kepala dan tangan yang banyak, wajah-wajah menyeramkan sehingga keseruan klimaks yang naratif pada teks sepadan dengan klimaks visualnya yang menghadirkan dualitas superior melawan inferior.

Hal yang sama juga dapat dibaca pada kasus Gambar 2. Karya ini dimuat dalam buku katalog manuskrip Bali bagian I ditulis oleh Hinzler 1986 dengan keterangan "Nakula (right) kneels in front of Salya (left). Salya restrains his wife (centre) from stabbing herself to death and embraces her." Sebuah potongan fragmen tunggal. Fragmen tunggal merujuk kepada perkembangan seni lukis tradisional Bali yang dikenal memiliki adegan naratif yang banyak dalam satu medium gambar namun 
kemudian disederhanakan menjadi satu adegan pada satu medium sebagaimana banyak di jumpai pada karya-karya bertahun sekaitar 1870-awal 1900 oleh pelukis maestro dari Bali Utara bernama I Ketut Gede Singaraja dan pada tahun 1930an dikembangkan oleh I Gusti Nyoman Lempad di Ubud.

Gambar 2. Adalah potongan fragmen dari Salya Parwa ketika Nakula dari keluarga Panca Pandawa mendatangi perkemahan Prabu Salya di malam hari dalam suatu rentangan masa perang Bharatayudha, mengetahui suaminya akan berperang dan memberitahukan kelemahan Salya adalah pada pustaka Kalimosadha milik Dharmawangsa maka Dewi Satyawati mengancam Prabu Salya dengan menghunus keris dan akan melakukan bunuh diri jika Prabu Salya berangkat ke medan perang keesokan harinya. Kisah ini tergolong populer dan menjadi favorit sebab ceritanya menghadirkan plot kesedihan, percintaan, kepahlawanan, kematian dan kesetiaan oleh sebabnya penggambaran Salya Parwa jika tidak menghadirkan mesatya Dewi Satyawati maka pasti menggambarkan eposide gugurnya Prabu Salya dengan pustaka Kalimosadha pada dadanya dan jika tidak demikian sudah pasti menghadirkan penggambaran adegan ranjang Prabu Salya dengan Dewi Satyawati. Pada kasus Gambar 2, adalah menghadirkan narasi sebelum percintaan dimulai meski digambarkan lebih erotis juga dramatis dengan menghadirkan Nakula pada adegan.

Efek narasi pada lukisan I Ketut Gede Singaraja ini juga membuat gambar terlihat tidak realistis terutama pada bagian Prabu Salya yang sedang memeluk Dewi Satyawati di dalam sebuah bangunan bale bertiang empat, figur tokoh dibuat menjadi lebih besar daripada bangunan, sedangkan lantai dibuat tampak atas sehingga blok bata terlihat jelas. Di dalam RWD yang menganut multiple-perspective bahwa yang menjadi utama adalah adegan Prabu Salya dengan Dewi Satyawati juga kehadiran Nakula yang berlutut di luar bangunan, narasi utama diberikan porsi lebih besar daripada bangunan yang akan menuntun kita untuk fokus terhadap suatu adegan peristiwa dan tidak fokus pada penggambaran latar depan juga latar belakang.



Gambar 2. Cod Or.3390-303 SalyaSatyawati-Nakula

Foto atas kebaikan Hedi Hinzler

Penggunaan matra waktu pada adegan ini sangat simbolik, I Ketut Gede Singaraja menggunaakan burung hantu yang ikonik sebagai penanda waktu malam hari. Sebagaimana yang kita tahu bahwa ketika Nakula mengendap ke tempat pamannya yaitu Prabu Salya dilakukan oleh Nakula pada malam hari setelah Sang Karna gugur pada sore harinya, pihak Pandawa tahu bahwa yang diangkat sebagai senopati setelah Karna adalah Prabu Salya, oleh sebabnya Nakula diutus menemui pamannya pada malam hari. Burung hantu menjadi cara wimba malam hari dalam fragmen ini, meskipun pada latar belakang tidak dibuat gelap sebagaimana logika waktu pada sistem NPM, oleh sebab itu keterbacaan momen malam hari disimbolkan dengan kehadiran burung hantu yang bertengger pada pohon di atas 
figur Nakula yang sedang memberi salam kepada paman dan bibinya.

Ekspresi wajah digantikan dengan gestur tubuh seperti gestur Prabu Salya yang tangan kirinya memegang payudara Dewi Satyawati, tangan kanan memegang tangan Dewi Satyawati yang menghunus keris, kaki kiri Prabu Salya diangkat dan mengikat kaki istrinya. I Ketut Gede Singaraja menggambarkan sebuah adegan keputusasaan, lirih, sekaligus erotik yang tentu saja acuannya adalah teks kakawin-nya.

Sebagai rujukan teks kakawin dalam penelitian ini mempergunakan Kakawin Bharatayudha terbitan tahun 1989 oleh Dinas Pendidikan Dasar, Provinsi Daerah Tingkat I, Bali. Pada buku ini terbagi menjadi dua bagian yaitu kakawin dan terjemahan dengan bahasa Bali. Cerita tentang Prabu Salya sebagai senopati perang di pihak Korawa dimulai dari pasalin 36.

Sejalan dengan Gambar 2. Narasi cerita pertemuan Nakula dengan Prabu Salya tersurat pada bait ke-12, halaman 198 sebagai berikut:

"awāsta ṅway manke ri sukun ta ìhina rasa, oapan. yadyan inway wānya ri haji katoney raṇa sabhā, llwös pāpāniy drohaka hinaranān alpaka guru, mataynyan mahpātrĕm těkě makĕni těngěkni nakula//"

Terjemahannya:

"Keadaan saya saat ini, saya bersedia mati di kaki paman yang saya sentuh

Meskipun saya tidak takut terhadap paman hal itu dilihat di medan laga

Amat menderita seseorang yang dikatakan lancang dan berani terhadap orang tua

Oleh sebab itu silakan penggal saja kepada si Nakula ini"

Adegan Dewi Satyawati yang menghunus pedang termuat dalam Pasalin 38, bait ke-1, halaman 212 sebagai berikut:


mamrih aměkul, dhū dyah satyawatìnku māsku kita jīwitañku hinaris; hāh ndi ntuhwa wuwuskw i say nakula jātya nin wan் asĕgěh, kintwīkin wĕnaì ànludhāina ri huripkw asambhawa dahat.//"

Terjemahannya:

"Dewi berkata sembari memegang keris berniat menikam diri, Raja Salya lalu memeluk dan memberi perhatian,

Salya berkata dengan lemah lembut: 'Duhai Satyawati belahan jiwaku',

Ah mustahil mengenai ucapanku terhadap Nakula, sebenarnya hanya memberi jamuan,

meskipun saat ini untuk keberhasilannya ingin mencabut nyawaku, mustahil sekali."

Dengan membaca teks kakawinnya kemudian membaca bahasa rupa lukisan I Ketut Gede Singaraja (Gambar 2) maka matra waktu tidak hanya disimbolkan dengan burung hantu bertengger di pohon, matra waktu juga bersifat matra waktu gabungan, hal itu dikarenakan di dalam teks pertemuan antara Nakula dengan Prabu Salya sebenarnya diceritakan tanpa kehadiran Diah Satyawati begitu juga sebaliknya ketika Prabu Salya menenangkan hati istrinya yaitu Diah Satyawati di peraduan yang di dalam teks kakawin diceritakan bahwa Nakula sudah pamitan dengan Prabu Salya setelah diberitahu kelemahan dari Prabu Salya dan Nakula kembali pulang ke tempat pasukan Pandawa. Oleh sebab itu, sudah tentu adegan Gambar 2 jika dibaca melalui sistem NPM maka dapat dikatakan tidak logis sebab tidak sesuai dengan teks kakawin, akan tetapi dengan pola matra waktu gabungan pada sistem pembacaan RWD maka waktu dapat dikombinasikan sekaligus antara pertemuan Nakula menghadap Prabu Salya dengan percintaan Prabu Salya bersama Diah Satyawati. 
I Ketut Gede Singaraja menggabungkan dua teks menjadi satu kesatuan sekaligus menggabungkan matra waktu secara bersamaan ke dalam satu bingkai fragmen gambar. Dengan demikian satu gambar dapat terdiri dari dua teks atau lebih. Pola-pola semacam ini dapat kita temukan pada relief di candi dan tentu pada seni lukis tradisi Bali.

Sejalan dengan rumusan proposisi pemikiran Wittgenstein tentang teori gambar menyatakan bahwa proposisi itu adalah gambaran realitas (kenyataan) dunia maka jika memahami proposisi itu berarti sekaligus juga memahami keadaan suatu peristiwa secara faktual (fakta) yang dihadirkan melalui suatu proposisi tersebut. Demikian juga dengan mudah akan dapat dipahami proposisi itu tanpa perlu dijelaskan lagi suatu pengertian yang terkandung di dalamnya (Kaelan, 2009:99). Ikon waktu malam hari berupa burung hantu sekaligus menjadi sebuah proposisi akan realitas narasi pada adegan pertemuan Nakula dengan Prabu Salya, ikonik burung hantu secara ikonologi dimaknai dan identik terhadap matra waktu malam hari.

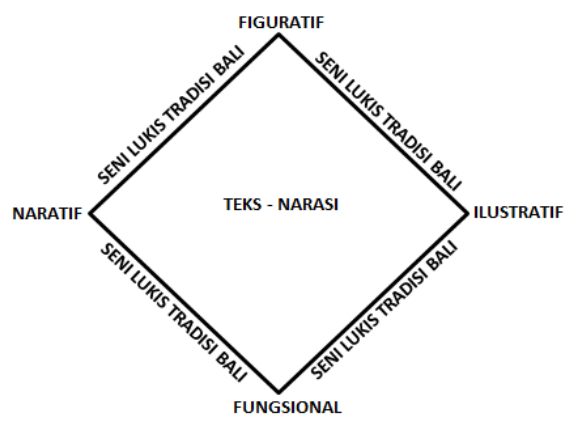

Gambar 3. Pola Pengaruh Narasi Terhadap Seni Lukis Tradisi Bali

Sumber: Dewa Gede Purwita

Sebuah narasi pada teks nyatanya memang sangat berpengaruh terhadap daya reinterpretasi pelukis tradisional Bali, tahap yang penting mempengaruhi hasil akhir dari sebuah lukisan adalah tahap memaknai ulang certia yang terkandung pada sebuah teks. Narasi juga mempengaruhi gaya penggambaran figur tokoh-tokoh yang lebih banyak dibuat dengan pola wajah tampak $3 / 4$ sedangkan bagian tubuh kebawah digambarkan tampak penuh ke depan dengan telapak kaki menyamping. Pola seperti ini merupakan pembentukan ulang atas pola wayang kulit dengan wajah yang dibuat en-profile.

Figuratif memunculkan representasi yang menyiratkan hubungan dari sebuah gambaran terhadap sebuah objek yang menjadikannya sebagai ilustrasi, juga menyiratkan sebuah hubungan antara satu gambaran dengan gambaran lainnya, dengan kata lain, hubungan saling keterkaitan unsur rupa dalam sebuah gambar yang membentuk ilustrasi. Narasi adalah korelasi dari ilustrasi. Sebuah cerita selalu diselipkan di dalamnya (Deleuze, 2002: 2). Fungsional merujuk kepada fungsi sosial seni yang merujuk pada kegunaan segala sesuatu (karya seni) bagi kehidupan suatu masyarakat, di dalamnya disebut fungsi manifest oleh Robert K. Merton sebagai konsekuensikonsekuensi yang diharapkan dari suatu tindakan sosial atau situasi sosial (Wrahatnala, 2019:32).

Teks yang memuat narasi menjadikan seni lukis tradisi Bali sebagai suatu yang fungsional secara tekstual sebagai penyampai pesan, secara kontekstual tentu berfungsi sebagai persembahan bagi pelukisya, sebagai bagian dari dekorasi suatu bangunan, sekaligus sebagai karya seni.

\section{SIMPULAN}

Seni rupa tradisi dalam hal ini lukisan Bali memiliki empat struktur pembentukya yaitu naratif, figuratif, ilustratif, dan fungsional. Aspek narasi yang termuat dalam suatu teks juga memiliki peranan yang sangat penting membentuk gaya bahasa rupa seni lukis tradisi Bali, melalui pembcaan dengan 
sistem RWD (Ruang-Waktu-Datar) maka akan dapat dibaca efek kehadiran narasi sebagai pembentuk lukisan seperti mempergunakan multiple-perspective, keirasionalan yang menjadi rasional, matra waktu, gestur sebagai pengganti ekspresi wajah untuk menandakan keadaan psikologis tokoh figur dalam cerita. Dengan demikian untuk membaca seni lukis tradisi Bali yang harus diperhatikan adalah teks yang melatar belakangi sebuah gambar, dalam istilahnya adalah kehadiran realitas teksnarasi dan realitas bahasa gambar.

Penelitian ini tentu saja membuka banyak peluang untuk penelitian selanjutnya mengenai keterkaitan narasi dalam sastra dan juga seni rupa serta bagaimana teori bahasa rupa mampu membaca kompleksitas seni rupa Bali dari masa klasik hingga kontemporer yang memang sangat sesuai dengan perkembangan wujud karya rupa dalam alur sejarah seni rupa Bali.

\section{DAFTAR PUSTAKA}

Adams, Laurie Schneider. (2001). A History of Western Art. New York: Mc Graw Hill.

Atika Laila, T., Silvana Sinar, dan T.Thyrhaya Zein. (2021). Hubungan Inter-semiotik Teks Verbal Dan Visual Pada Nasi Hadap-Hadapan. Bahterasia 2 (1).

Deleuze, Gilles. (2002). Francis Bacon The Logic of Sensation. New York: Continuum.

Dinas Pendidikan Dasar. (1989). Bharatayudha: Kakawin miwah Teges Ipun. Denpasar: Provinsi Daerah Tingkat I Bali.

Dwija Putra, I Dewa Alit. (2018). "Menelusuri Jejak Rupa Wayang
Klasik Bali". Jurnal Rupa 3(2) 04. hal, 130-149.

Fischer, Joseph \& Thomas Chooper. (1998). The Folk Art of Bali The Narrative Tradition. Kuala Lumpur: Oxford University Press.

Harris, Jonathan. (2006). Art History the Key Concepts. New York: Routledge.

Hinzler, H.I.R. (1986). Catalogue of Balinese Manuscript In The Library of The University of Leiden and Other Collection In The Netherlands Part I. Leiden: Leiden University Press.

Hinzler, H.I.R. (1986). Catalogue of Balinese Manuscript In The Library of The University of Leiden and Other Collection In The Netherlands Part II. Leiden: Leiden University Press.

Kaelan. (2009). Filsafat Bahasa Semiotika dan Hermeneutika. Yogyakarta: Penerbit Paradigma Yogyakarta.

Irianto, Agus Maladi. (2017). "Kesenian Tradisional Sebagai Sarana Strategi Kebudayaan di Tengah Determinasi Teknologi Komunikasi”. Nusa 12(1), hlm. 90100.

Purbasari, Sophia., et al. (2013). "Kajian Proses Adaptasi Narasi Visual 'Scott Pilgrim vs The World' dari Komik Menjadi Film”. Wimba, Jurnal Komunikasi Visual dan Multimedia. 5(1) hlm. 89-105.

Purwita, Dewa Gede. (2019). Ngedum Karang, Jajar Wayang, Ceraki: Membedah Kerja Desain Pada Seni 
Lukis Wayang Kamasan. SENADA (Seminar Nasional Desain Dan Arsitektur), 2, 209-215. Retrieved from

https://eprosiding.idbbali.ac.id/inde x.php/senada/article/view/135

Rafsanjani, Asyhari. "Figur-figur Wayang Sebagai Inspirasi dalam Karya Seni Lukis". Arty: Journal of Visual Arts 3(1), hlm. 34-39.

Rohidi, Tjetjep Rohendi. (2011). Metode Penelitian Seni. Semarang: Cipta Prima Nusantara.

Saidi, Acep Iwan. (2007). "Mengenal Narasi dalam Seni Rupa". Jurnal Sosioteknologi 12(6), hlm. 297302.

Suarka, I Nyoman., et al. (2012). Lukisan Sutasoma di Bale Kambang Kerta Gosa, Klungkung, Bali. Denpasar: Pusat Kajian Bali UNUD.

Tambrani, Primadi. (2012). Bahasa Rupa. Bandung: Penerbit Kelir.

Yudoseputro, Wiyoso. (2008). JejakJejak Tradisi Bahasa Rupa Indonesia Lama. Jakarta: Yayasan Seni Visual Indonesia.

Wrahatnala, Bondet. (2019). "Fungsionalisme Struktural dalam Kajian Etnomusikologi”. Laporan Akhir Penelitian Pustaka. Surakarta: Institut Seni Indonesia Surakarta. 